\title{
Evaluation of Uncertainty in Hybrid Plants, Including Wind Turbine, Photovoltaic, Fuel Cell, and Battery System using Fuzzy Logic
}

\author{
MiladGheydi ${ }^{1}$, Reza Effatnejad ${ }^{2 *}$ and Parviz Ramezanpour ${ }^{2}$ \\ 'Department of Electrical Engineering, Islamic Azad University, Science and Research \\ Branch, Alborz, Iran; gheydi.m@gmail.com \\ 2Department of Electrical Engineering, Islamic Azad University, Karaj branch, Alborz, Iran; \\ Rezaeffatnejad@yahoo.com, parvizramezanpour@yahoo.com
}

\begin{abstract}
This paper examines the possibility of hybrid plants with a variable consumption in necessary conditions. The use of an adaptive controller includes fuzzy controller with increasing the high-reliability of system as an appropriate option. In his study inputs are voltage conditions and power; output variables include the operation of fuel cell and renewable energies. In this investigation, the objective function is the possibility and the ability of working in low and full load conditions along with the changes in renewable energies conditions. These controllers help to use a controller for hybrid systems. Consequently, communication of this situation by a central controller would be possible. Changes in wind speed and also the inherent changes in photovoltaic system are created during the simulation process. The system should be able to comply with the existing abnormal terms in addition to providing the electricity to the load. In a way that it can provide the required power through the commands which are transmitted from system controllers to AC and DC subsystems and eventually the system reach to a stable condition in a short period of time. In this case it is so important that the essential parameters of the network remain stable. This stability will be illustrated through the stabilization of the line voltage in 1 p.u and also restoring the frequency to its pervious condition. The active power control and voltage controller transmit the commands to the other controlling part which is an interface between two AC and DC systems in order to control the network values. A PID controller was used for controlling parameters in active power regulator. These parameters are designed with fuzzy logic algorithm.
\end{abstract}

Keywords: Fuel Cell, Fuzzy Logic, PV, Renewable Energy, Uncertainty, Wind Turbine

\section{Introduction}

Today, renewable energies are known as suitable sources for a green energy economy. These sources can include wind turbines, PhotoVoltaic systems (PV), and fuel cells. When these types of energy are used individually, they have some restrictions. The energy produced by wind turbines and PV systems depends significantly on climate. The restriction on wind turbines is wind speed and in the PV systems is sunlight. In addition, saving the energy produced by a wind turbine and a PV system is a difficult task. Solving the problems of renewable energies requires integrating them into a network and using them in a hybrid form. This will lead to compensating the restrictions of each module by other modules. In this way, their use will increase system reliability and efficiency. In this type of system, consideration of uncertainty in power supply during changes in energy resources is very important. Overall, hybrid systems are the combination of renewable energy systems and energy storage systems. Besides, using them in a small scale in distribution networks is on the rise. In addition to the PV system and the wind

${ }^{*}$ Author for correspondence 
turbine, Proton Exchange Membrane (PEM) fuel cells are also a good option to produce energy by using electrolysis of water. PEM fuel cell is a suitable option, for using in high density and operating temperature in comparison to other types of fuel cells in such networks. Saving energy in an emergency or injecting it into the desired network is one of the other important features of hybrid systems; therefore, battery is one of the essential factors in such systems. Furthermore, super capacitors are also used in some systems. Readers can learn more in this field by looking up references ${ }^{1-5}$.

\section{System Description}

In a general survey, the system consists of distributed generation sources including wind turbine, battery for energy storage, PV system, fuel cell, electrolyser with linear load, and synchronous machine coupled with a Diesel Generator (DG). This system has two parts: the threephase system (AC) and DC system. These two parts are exchanging energy with each other through a central controller that controls the active power. Both these parts are connected to power system. After running, the stability between the AC and DC parts is a very important issue. Consequently, the aims of this system are to establish an appropriate change of power between load and permanent resources and also possibility of different distributed resources together. Three important variables in the study of the stability of this system are as follows: 1- Stability of voltage in three-phase system. 2-Stability of voltage in DC link. 3- Stability of frequency in three-phase system. The system consists of three parts; in order to control the system, the first part is a governor that is coupled with a diesel engine to control the frequency. The Second part is a voltage controller to control the system voltage. The last part, Active Power Regulator (APR) system, is a PID system that has been designed with a fuzzy logic algorithm. The first and the second parts are the ordinary controllers in most of island systems. In fact, they are integral parts in such systems. Both of them are coupled with synchronous machine and governor by producing both mechanical and electrical power to help the control of frequency and voltage in the system. The last part represents the connection between AC and DC parts. APR that always considers rising and falling of electrical and mechanical powers is compared to reference values. PID controller is for reducing these variations. In fact, two factors cause changes in the amount of energy sources; the first is local variations (like changing in wind speed and main load) and the second is initial working in the system (like starting after fault occurrence in the system). The single line diagram of the system is shown in Figure 1. In this study, there are two changes. The first is the change in wind speed at the $10^{\text {th }}$ second and the second is load shedding at the $15^{\text {th }}$ second.

\section{PV Model}

A single PV cell is composed of series resistance, internal parallel resistance, parallel diode, and photo-generated current source. The PV system characteristics are according to the following equations ${ }^{6}$ :

$$
I_{s}=I_{s c}-I_{o}\left(e^{\frac{q\left(R_{w} I_{s}+V_{s}\right)}{A K T}}-1\right)-\frac{R_{s} I_{s}+V_{s}}{R_{s h}}
$$

where, $I_{s}$ is the output current, $I_{o}$ is the reverse saturation current, $I_{s c}$ is the generated current under a given intensity, $V_{s}$ is output voltage of the PV cell, $A$ is the ideality

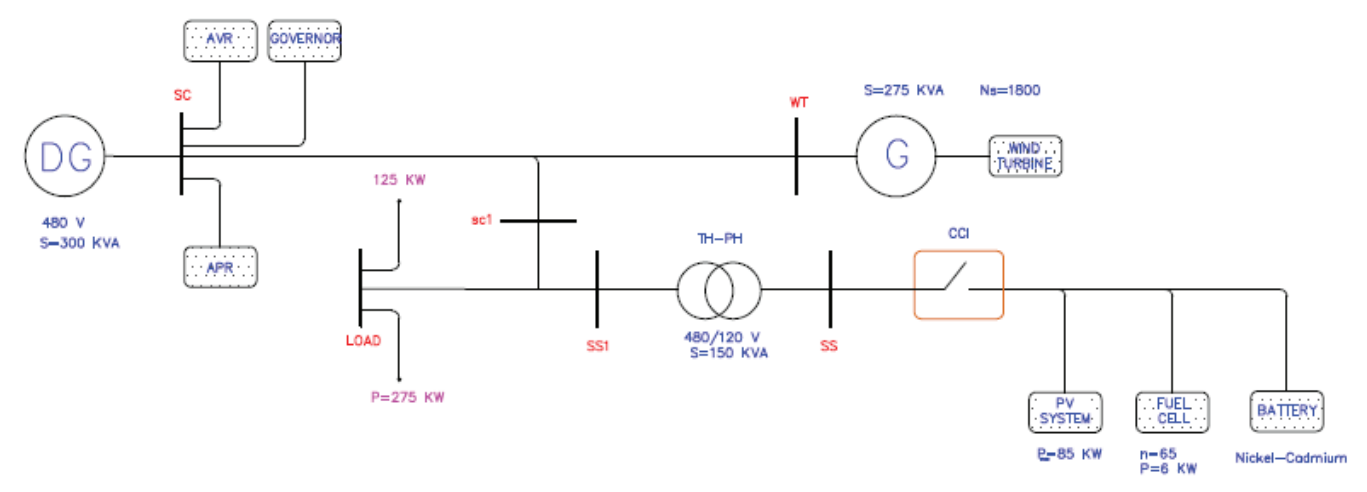

Figure 1. The single line diagram of system. 
factor for a p-n junction, $K$ is the Boltzmann's constant, $q$ is the charge of an electron, $T$ is the temperature rise, $R_{\mathrm{s}}$ is internal series resistance, and $R_{s h}$ is are parallel resistance. Equivalent circuit of single PV system is shown in Figure 2.

The $I_{o}$ varies with temperature and can be expressed as the following ${ }^{6,3}$ :

$$
\begin{gathered}
I_{0}=C_{D} T^{3} e^{\left(\frac{-\ell E_{G}}{A K T}\right)} \\
I_{p h}=5.46 \times 10^{-3} E_{t p}[1+0.001(T-298)]
\end{gathered}
$$

where, $E_{t p}$ is the intensity in $\mathrm{mW} / \mathrm{cm}^{2}, C_{D}$ is the diffusion capacitance, and $E_{G}$ is the band-gap energy of the semiconductor used in the panel. The simulation diagram of the PV system is shown in Figure 3.

\section{Wind Turbine Model}

According to the laws of aerodynamics, output power in wind turbine can be expressed as the following ${ }^{6}$ :

$$
\begin{gathered}
P_{t}=\frac{1}{2} \rho \pi \lambda C_{p}(\lambda, \beta) v^{3} R^{2} \\
\lambda=\frac{R \omega_{m}}{v}
\end{gathered}
$$

where, $\rho$ is the air density, $C_{P}$ is the wind power utilization coefficient, $R$ is the radius of wind turbine blades, and $v$

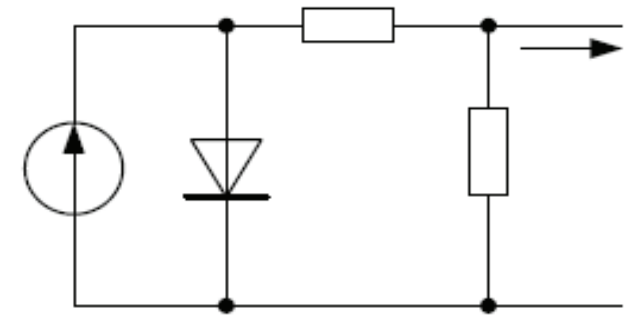

Figure 2. Equivalent circuit of single PV cell'. is the wind speed. The tip-speed ratio of wind turbine is written by Khan and IQbal':

The change in the rotor speed $W_{m}$ steadies the value of $C_{p}$ at the maximum to produce available optimum power. These changes are proportional to changes in wind speed V. The value of $X_{m}$ maximum output power at various speeds for a wind turbine is considered. For example, for a typical wind turbine, the obtained data is used to relate the maximum output power $P_{\max }$ to $x_{m}$ using a polynomial curve fit, as shown below ${ }^{8}$ :

$$
P_{\max }=0.0005 \omega_{m}^{3}-0.00125 \omega_{m}^{2}+0.7 \omega_{m}-74.6 w
$$

$w_{m}$ is the rotor mechanical speed. The simulation diagram of the wind turbine is shown in Figure 4.

\section{Fuel Cell Model}

In this paper, a PEM fuel cell stack is designed. A polymer membrane is used as the electrolyte in fuel cell; and air is used as an oxidant. The pressure of cell is atmospheric and the temperature is $70^{\circ} \mathrm{C}^{8}$. Characteristics of the fuel cell are shown in Figure 5.

For having an economical fuel, placing it in the areas that have low efficiency should be avoided. The hydrogen consumption of the fuel cell can be expressed as the following ${ }^{2}$ :

$$
M_{H 2}=\frac{1}{E_{l o n, H_{2}}} \int \frac{P_{f c}}{\eta_{f c}\left(P_{f c}\right)} d t
$$

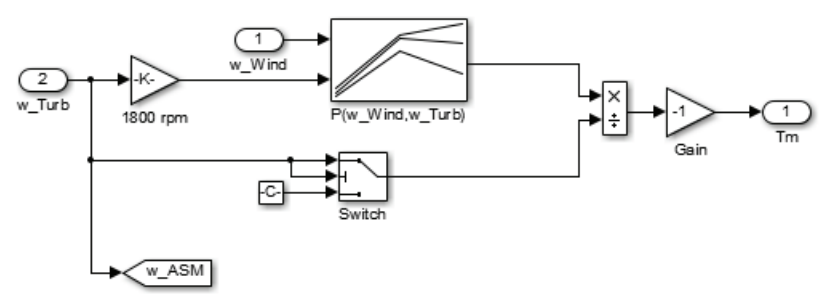

Figure 4. The simulation diagram of wind turbine model.

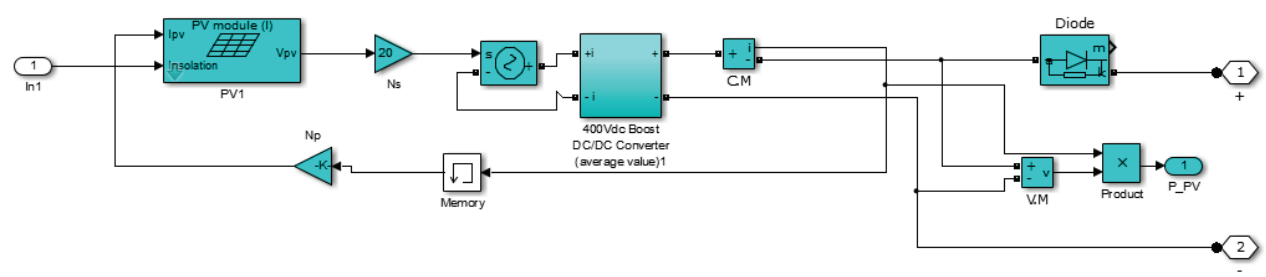

Figure 3. The simulation diagram of PV system model. 
where, $\eta_{f c}$ is the efficiency of the fuel cell, $E_{l o w, \mathrm{H} 2}$ is the lower heating value of hydrogen, $M_{H 2}$ is the hydrogen mass, and $P_{f c}$ is the output power of fuel cell. The simulation diagram of the fuel cell is shown in Figure 6.

\section{Electrolyser Model}

With passing of the electric current between two electrodes, the water can be analyzed into its constituent elements. The electrochemical reaction of water electrolysis is as the following?:

$$
\mathrm{H}_{2} \mathrm{O}+\text { electricalenergy } \Rightarrow \mathrm{H}_{2}(g)+\frac{1}{2} \mathrm{O}_{2}(g)
$$

According to Faraday's law, the value of producing hydrogen in electrolyser directly depends on electrical current electrolyser circuit as it is shown in the following ${ }^{12}$ :

$$
\eta_{H_{2}}=\frac{\eta_{F} n_{c} i_{e}}{2 F}
$$

where, $\eta_{F}$ is faraday efficiency, $F$ is faraday constant, $n_{c}$ is the number of electrolyser cells in series, $n_{\mathrm{H} 2}$ is produced hydrogen moles per second, and $i_{e}$ is electrolyser current. The maximum value of hydrogen produced in electrolyser is introduced as a practical mode for Faraday efficiency. Assuming that the operating temperature of electrolyser is $40^{\circ} \mathrm{C}$, the Faraday efficiency is expressed as the following ${ }^{4}$ :

$$
\eta_{F}=96.5 e^{\left(0.9 / i_{e}-75.5 / i_{e}^{2}\right)}
$$

According to the equations (9) and (10), a simple electrolyser model is developed by using Simulink, which is illustrated in Figure 7.

\section{Hydrogen Storage Tank Model}

Electrolyser provides the required hydrogen for the fuel cell. This process is provided according to the relation between the value of required hydrogen and the output power of the fuel cell system. The difference between
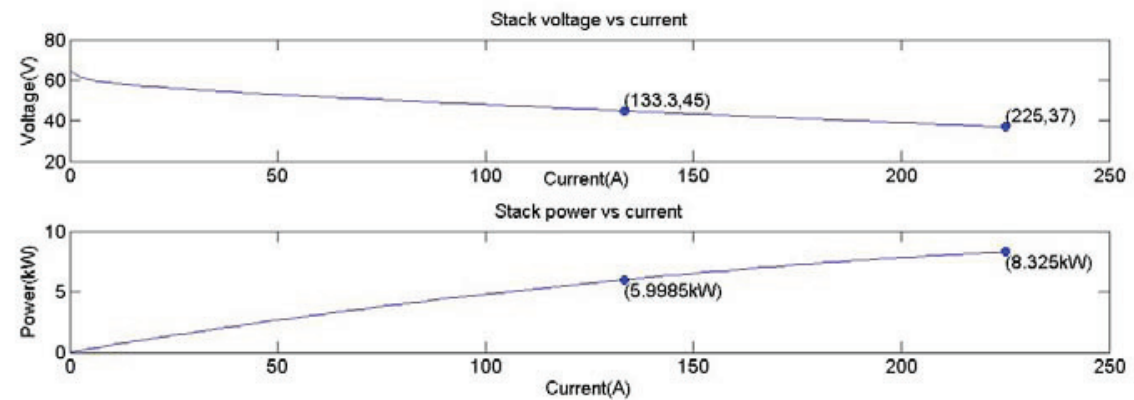

Figure 5. Characteristics of the Fuel cell.

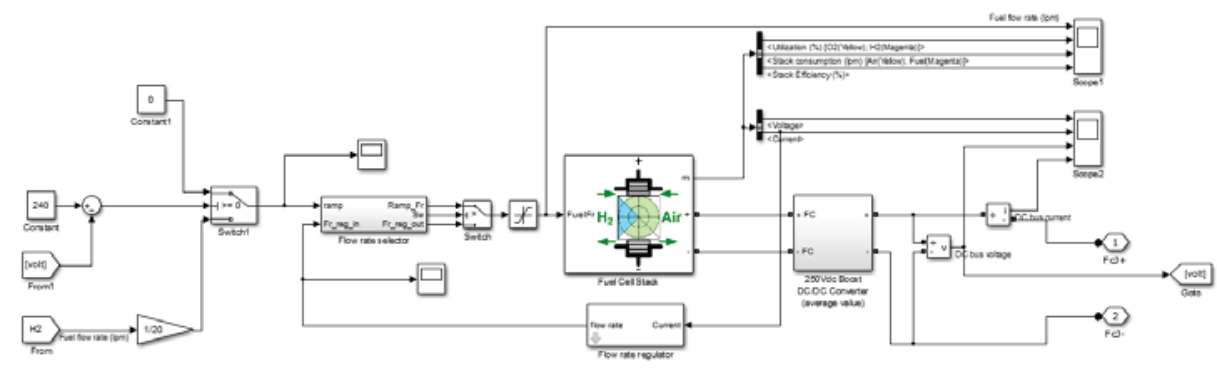

Figure 6. The simulation diagram of fuel cell model.

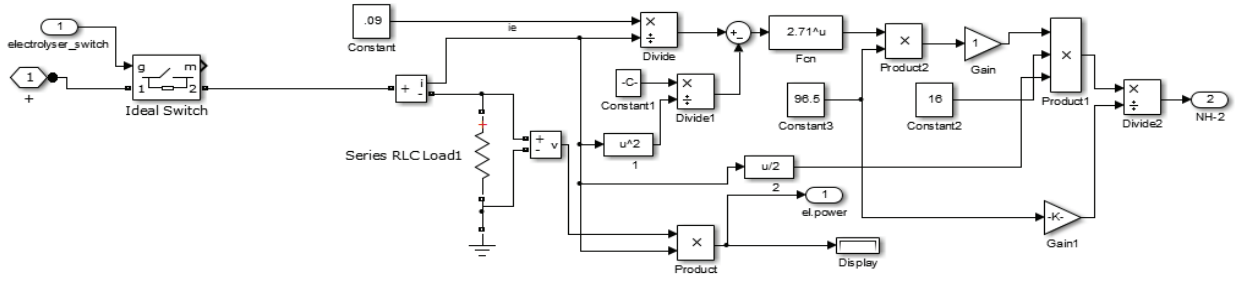

Figure 7. The simulation diagram of the electrolyser model. 
the produced and consumed value moves directly towards hydrogen storage tank. Hydrogen storage tank model directly calculates the pressure of tank by using the pressure on hydrogen tank. Dynamics of such a system can be written as the following ${ }^{12,13}$ :

$$
P_{b}-P_{b i}=Z \frac{N_{H_{2}} R T_{b}}{M_{H_{2} V_{b}}}
$$

where, $N_{H 2}$ is hydrogen moles per second delivered to the storage tank, $V_{b}$ is volume of the tank, $P_{b i}$ is initial pressure of the storage tank, $M_{\mathrm{H} 2}$ is molar mass of hydrogen, $P_{b}$ is the pressure of tank, $R$ is universal gas constant, $T_{b}$ is operating temperature, and $Z$ is compressibility factor as a function of pressure. The Simulink version of the hydrogen storage model is depicted in Figure 8.

\section{Battery Model}

In this study the internal resistance model is used. In comparison with the super capacitor, the battery has the features of high energy density and relatively low power density (the power density of battery is still 3-5 times higher than a fuel cell) 9 . The type of battery used in this study is Nickel-Cadmium. The major reason to limit charging and discharging is $\mathrm{R}_{\mathrm{b}}{ }^{2}$. $\mathrm{R}_{\mathrm{b}}$ is the internal resistance in battery. The battery model with an internal resistor and a voltage source is shown in Figure 9.

The State of Charge (SOC) is an important part in the battery in which the open circuit voltage and resistance are the nonlinear functions. These relationships are implemented as look-up tables with test data. The terminal voltage of battery pack can be expressed as the following ${ }^{2}$ :

$$
V_{b}=n_{b}\left(V_{o c}-R_{b} I_{b}\right)
$$

where, $V_{b}$ is terminal voltage of battery pack, $n_{b}$ is the number of battery cells, $V_{o c}$ is the open circuit voltage, $R_{b}$ is the internal resistance, and $I_{b}$ is the current flow out of the battery. If the battery pack is assumed to discharge some power $P_{b}$, then $I_{b}$ can be calculated as shown below ${ }^{4}$ :

$$
I_{b}=\frac{V_{o c}-\sqrt{V_{o c}^{2}-\left(4 R_{b} P_{b} / n_{b}\right)}}{2 R_{b}}
$$

where, $P_{b}$ is the battery power. The Simulink model of the battery system is shown in Figure 10.

\section{9. $\mathrm{AC} / \mathrm{DC}$ and DC/AC Model (CCI)}

In simulation model of this paper, after receiving the reference signal from APR unit, it is appropriate to switch

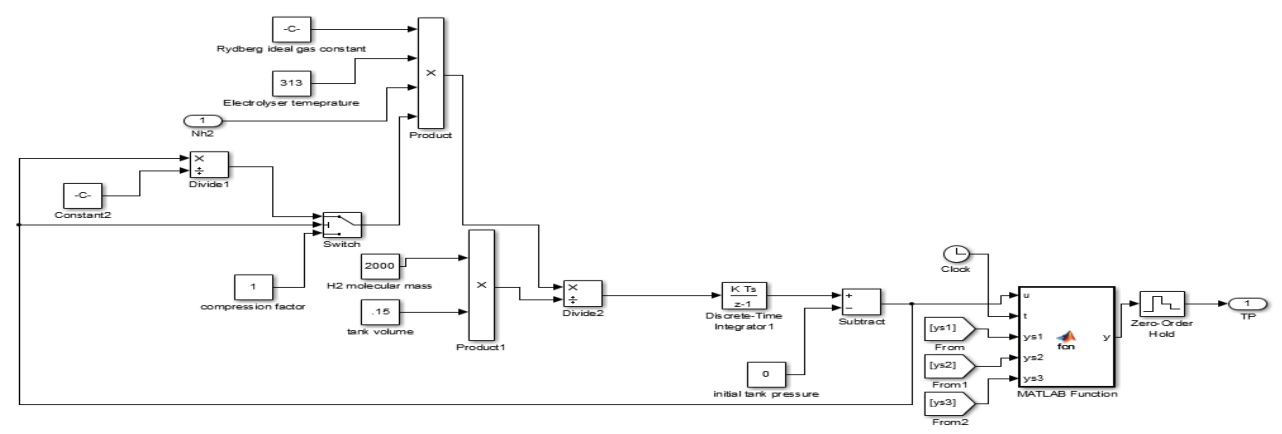

Figure 8. The Simulink model of the hydrogen storage tank.

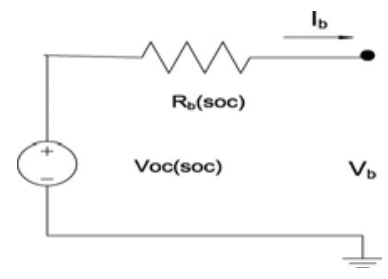

Figure 9. Internal resistance in battery model ${ }^{2}$.

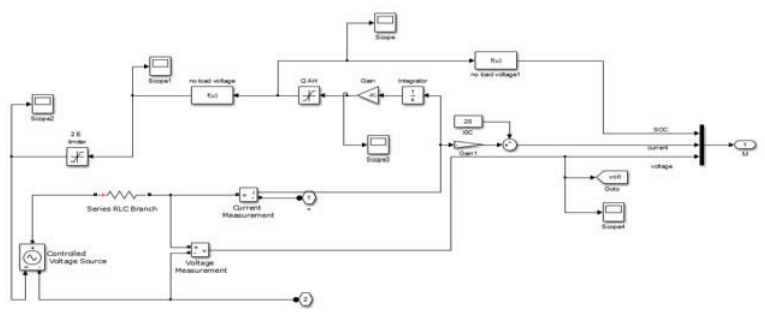

Figure 10. The Simulink model of the battery system. 
in order to receive the needed current from the DC part, or injection of the current applied to this part to complete the process in Current Control Inverter (CCI) part. In this section, after receiving power, voltage, and current signals, current values are transferred from abc reference to dq reference. Then, the desired value is compared with the reference value and error value; and after passing through a PI controller, it is transferred back to the abc reference frame. Reference voltage values are transferred to the PWM unit and pulses are produced. These pulses are transferred to a diode bridge and then switching is done from $\mathrm{AC} / \mathrm{DC}$ or DC/AC. The power flows through the DC/DC converter and DC/AC inverter ${ }^{5}$ :

$$
\begin{gathered}
P_{f c}=\frac{1}{\eta_{d c}\left(P_{D C}\right)} P_{D C} \\
P_{t o t}=\frac{1}{\eta_{a c}} P_{m}
\end{gathered}
$$

where, $\eta_{\mathrm{dc}}\left(P_{D C}\right)$ is the efficiency of the DC/DC converter, $\eta_{a c}$ is the efficiency of the DC/AC inverter, $P_{\text {tot }}$ is the total power that the DC bus delivers, and $P_{m}$ is the power of the AC motor.

\section{Synchronous Machine}

Diesel engine as a mechanical power generator with voltage control part as electrical power generator is coupled with a synchronous machine. Values of the reference frequency and reference voltage with a value of 1 p.u have been applied to the controller. The task of controller receives voltage signal, output RPM from synchronous machine, applying voltage by voltage control, mechanical force by the governor can control signals to synchronous machine and proportional power receives appropriate values.

\section{Active Power Regulator (APR)}

This part is designed by receiving the signal control from the governor and voltage control that is connected to the synchronous machine. These signals are compared with high bound related to the maximum convertible power to the AC system or additional Power in AC system. These values are transferred to switch the part (CCI). This controller acts as fuzzy PID. Fuzzy, the integral part is used to control power part; and fuzzy derivative is used to control the frequency part. PID controller is designed with fuzzy logic.

\section{Fuzzy Logic}

Fuzzy variables of controller include M, ML, and L. Based on the relative relations, the frequency and power errors have been collected in three functions. These three functions are negative, zero, and positive. Outputs have three levels: low, medium, and high. The control rule table is given in Table 1.

In Matlab/Simulink, fuzzy variables, domain and fuzzy control rule are written in Fuzzy Logic Toolbox.

\section{Results and Discussion}

The power between sources is designed by CCI, APR, and voltage controller. CCI is a device like switch, thereby, power between the AC and DC part is moving. The main aim of this study is to supply loads and stability of voltage and frequency in a system. The base value is assumed 1 p.u. Voltage has to be kept at 1 p.u after appearance of variations. To observe the dynamic behavior of the system, wind profile is shown in Figure 11. The shown dynamic model is nonlinear in 20 seconds. As seen in this figure, the wind speed decreases in the $10^{\text {th }}$ second. Reduction of wind speed to $7 \mathrm{~m} / \mathrm{s}$ is affecting generated power by a synchronous generator in wind turbine.

The next change will happen in 15 seconds. In this time the load of $125 \mathrm{~kW}$ is removed from the circuit. Although, by reducing power in a synchronous generator (wind turbine) the power is reduced, APR, governor, and voltage control in AC side adjust the power in system by CCI part. In this case, obviously the system will be unbalanced. Power conditions will change in the fuel cell, battery, and PV system. If we don't have fuel cell and PV system for supplying the system, DG has to supply

Table 1. Fuzzy control rule

\begin{tabular}{llll}
\hline E-EC & \multicolumn{1}{c}{ NEG } & \multicolumn{1}{c}{ ZERO } & \multicolumn{1}{c}{ POS } \\
\hline NEG & M-M-L & M-ML-L & ML-ML-ML \\
ZERO & L-L-ML & L-L-L & ML-ML-L \\
POS & ML-ML-ML & M-ML-M & ML-M-M \\
\hline
\end{tabular}

where E, error levels (the horizontal axis), is frequency error and EC (the vertical axis) is voltage error. The concept of $\mathrm{M}$ is high, $\mathrm{ML}$ is medium, and $\mathrm{L}$ is low. Values for the output from left to right are for $\mathrm{K}_{\mathrm{p}}, \mathrm{K}_{\mathrm{i}}$, and $\mathrm{K}_{\mathrm{d}}$ in PID system ${ }^{14}$. 
the loads. This means spending more fuel and cost. In spite of fuel cell, by PV system and battery and adapting them together these problems can be reduced. The governor injects mechanical power to the system to control frequency and voltage for constant excitation and line voltage by injecting electrical power. The necessary signals are received by the APR from the governor and the voltage control part; then, these signals are sent to CCI part to inject the power from/to DC part. Also, APR can control power between the diesel genarator and the wind turbine (AC parts).Controling frequency is shown in Figure 12.

As it can be seen in Figure 12, the mechanical power is in steady state in 10 seconds. After changing wind speed, mechanical power (frequency) of system becomes unbalanced. 10 seconds later, system will return to the normal condition. Voltage control also does the same thing to

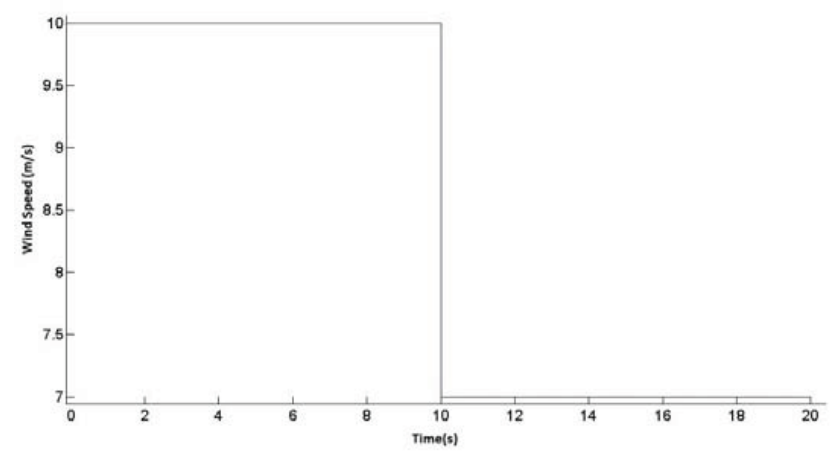

Figure 11. Wind profile used for system simulation.

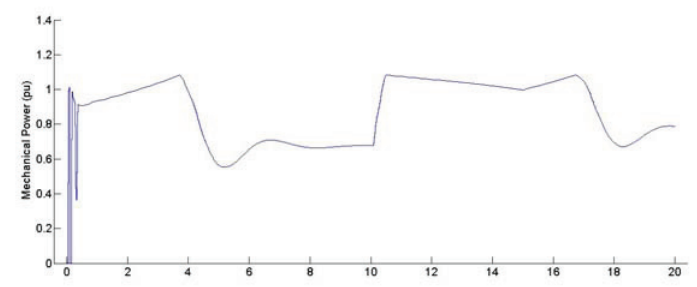

Figure 12. Mechanical power injected by APR.

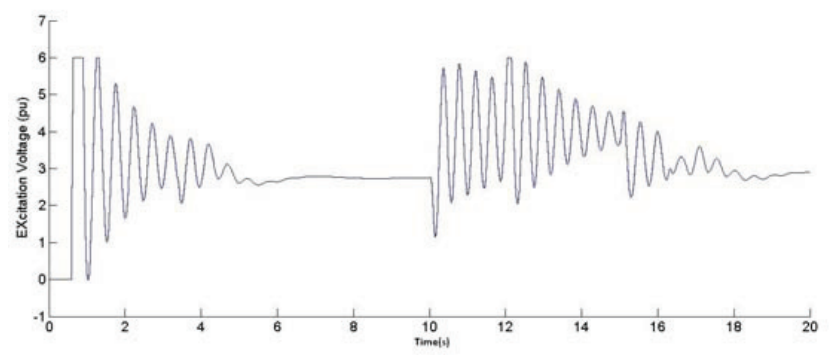

Figure 13. Excitation voltage in synchronous machine. improve the voltage. The voltage control is shown in Figure 13. Changes in the $15^{\text {th }}$ second with removing load $(125 \mathrm{KW})$ can also be seen.

After receiving a signal from the control units, appropriate switching between AC and DC part (CCI) must be performed. Total load demand is shown in Figure 14.

The CCI orders the flow of injection from the DC side or conversely, after receiving the required signals. According to the carried out orders, the value of transferred power during 20 seconds is simulated and also shown in Figures 15 and 16, with considering the variation of wind velocity in the battery system and PV. If the power demand is greater than the power available from the wind turbine, the fuel cell and PV system will satisfy the needed excess of power.

As it is shown in Figure 16, in the $10^{\text {th }}$ second the reduction of production occurs in the wind turbine and

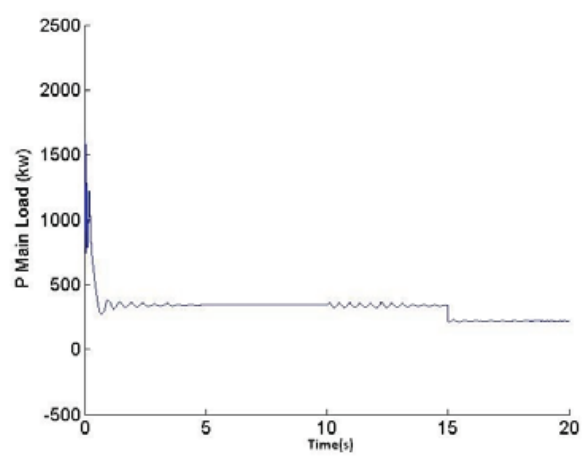

Figure 14. Total load demand of the user.

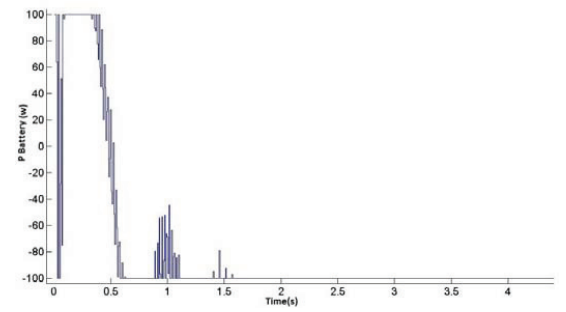

Figure 15. Battery system power during the simulation.

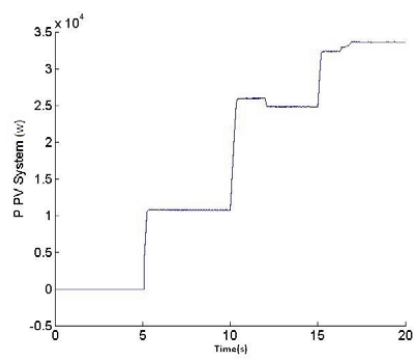

Figure 16. PV system power during the simulation. 
the $15^{\text {th }}$ second's load is removed from the system and the share of PV system and the supplied load demand is about $2.6 \times 10^{4} \mathrm{w}$. PV systems like wind turbines are highly dependent on natural elements. The amount of sunlight during the day has a considerable impact on them. In addition, increasing or decreasing of loads affects system performance. Excess of energy is stored in the battery. The amount of solar radiation is shown in Figure 17.

Hereby considering the battery being discharged and also the fuel cell producing energy, the value of production varies to reach $3.3 \times 10^{4} \mathrm{~W}$ in about 20 seconds. The state of charge in the battery, discussed in the previous section, is shown in Figure 18 and the current of the battery is shown in Figure 19.

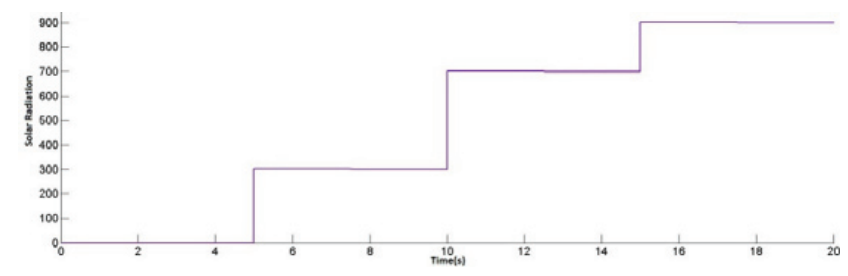

Figure 17. The value of solar radiation in PV system (signal builder).

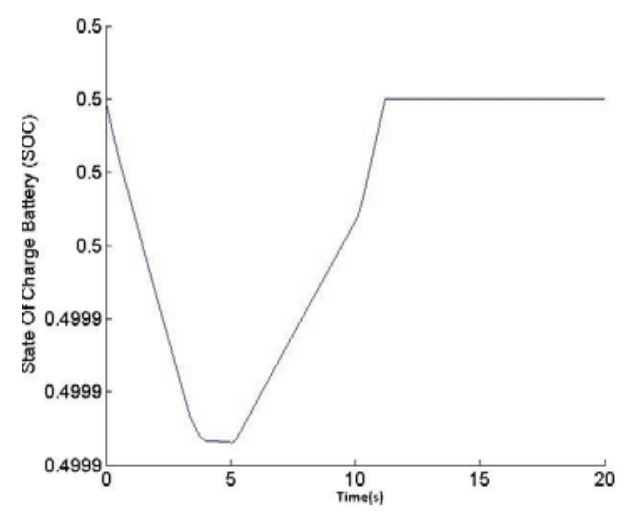

Figure 18. State of charge in battery during the simulation.

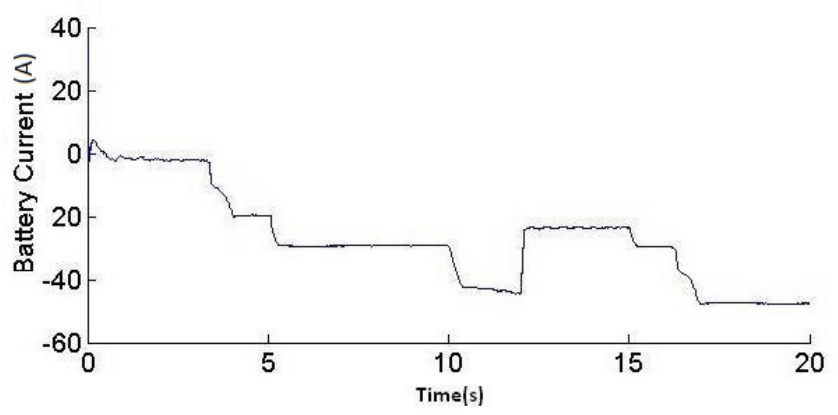

Figure 19. Battery current during the simulation.
The battery serves as a short-time power source to fulfill more power that cannot be satisfied by the fuel cell system. Fuel cell is one of the other sources of energy production, and fuel is produced by electrolyser in the hydrogen storage tank to supply its fuel. The amount of fuel and stack consumption are shown in Figures 20, 21, and 22.

Fuel Cell injects current to DC bus during the simulation. DC bus voltage is shown in Figure 23. The value of hydrogen moles is consumed by the fuel cell that is proportional to the power drawn from the fuel cell system. The value of hydrogen, stored in the storage tank, corresponds to the difference between the hydrogen produced by the electrolyser and the hydrogen consumed by the fuel cell system. The value of the produced power by synchronous

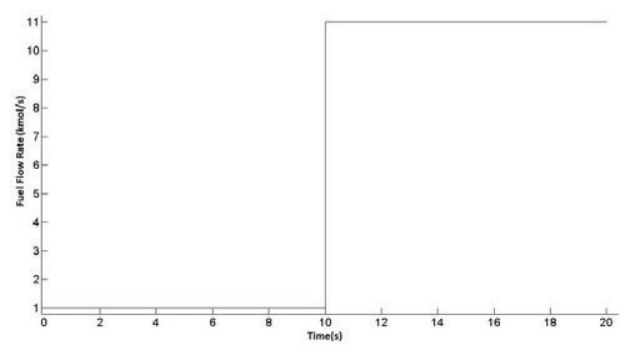

Figure 20. Fuel flow rate in fuel cell.

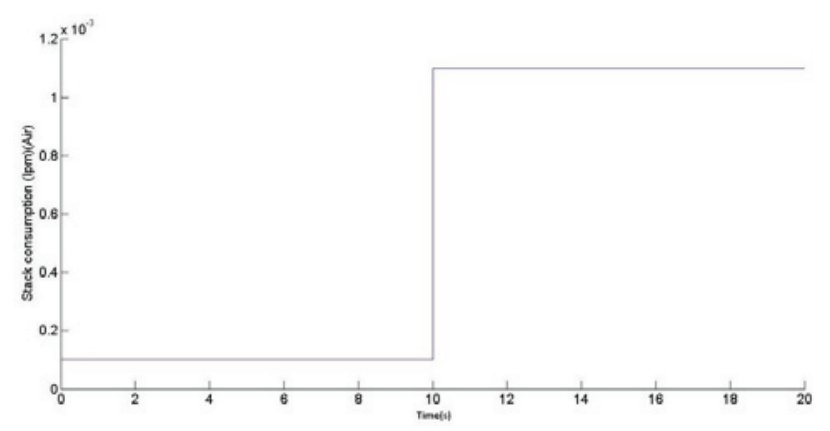

Figure 21. Stack consumption (Air) in fuel cell.

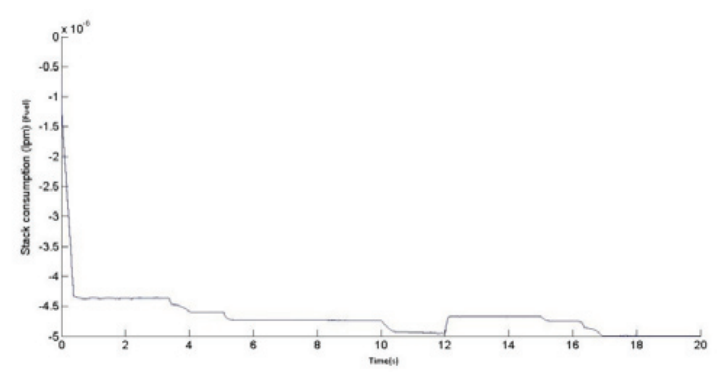

Figure 22. Stack consumption (fuel) in fuel cell. 
machine and also wind turbine in accordance with variations is shown in Figures 24 and 25. The line voltage should be kept around 1 p.u due to the changes. The stability of line voltage is shown in Figure 26.

As it is shown in Figure 26, the system voltage stability is well preserved. The line voltage has been studied using the classical method as shown in Figure 27. In this method the fuzzy logic is removed from the system and there is only the PID. Comparing the simulation using fuzzy logic method and classical method it can be observed that the fuzzy logic method brings the line voltage to its stability margin (1p.u) in a shorter time. In this case the reliability of the system is improved.

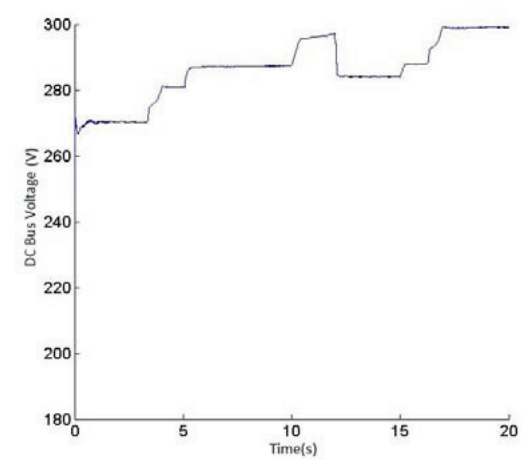

Figure 23. DC Bus Voltage.

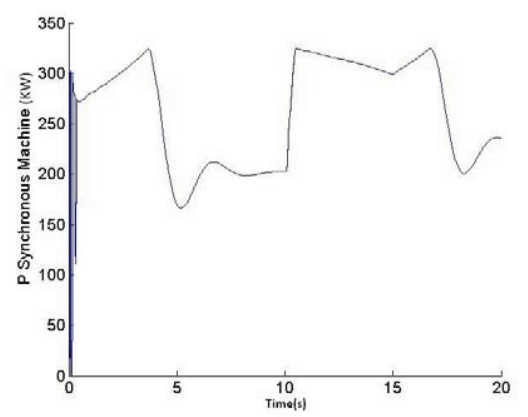

Figure 24. Synchronous machine power during the simulation.

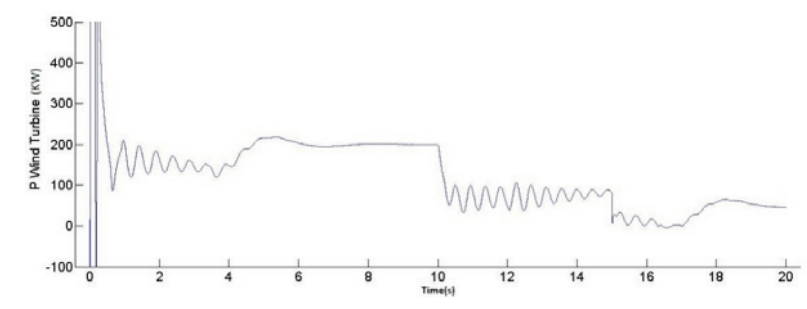

Figure 25. Wind turbine power during the simulation.
The inverter controls three-phase AC output voltage with a frequency of $60 \mathrm{~Hz}$ and DC output voltage. When both the wind turbine and the PV system are unable to supply the load demand, the stored hydrogen is supplied to the fuel cell. The use of power generated by the PV and wind turbine systems have priority in satisfying power demand over the one that is provided by the fuel cell system. If the total power, generated by the PV and wind turbine systems, is higher than the demand, the additional power will be used to charge the battery. The remaining power is used for the electrolyser through a power converter to generate hydrogen; also, the additional power generated by the wind turbine and PV system can be

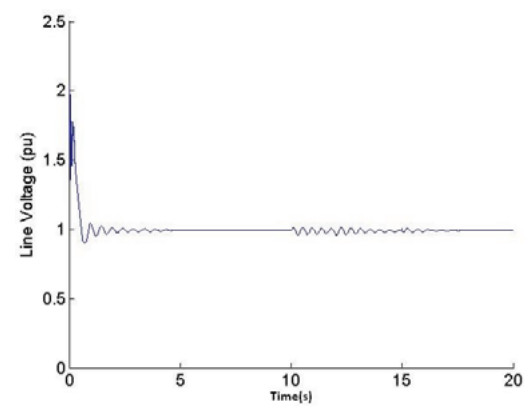

Figure 26. Line voltage in system with fuzzy logic model.

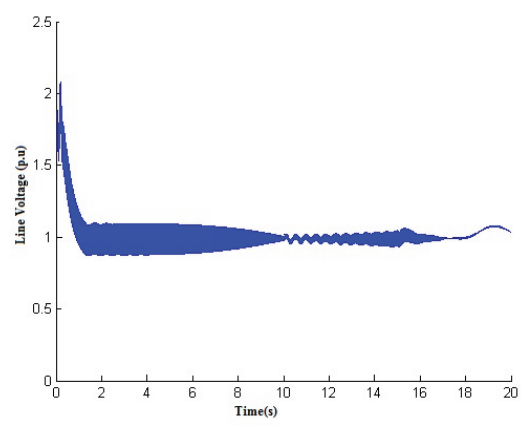

Figure 27. Line voltage in system with classical model.

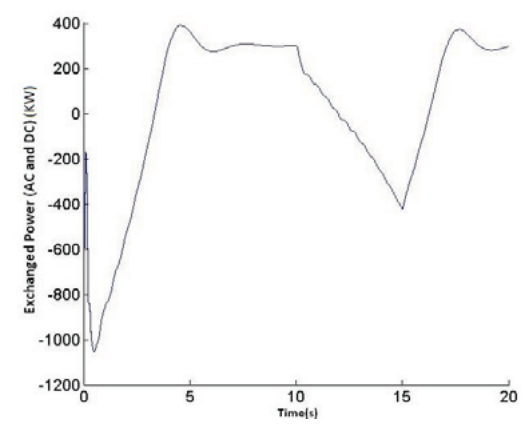

Figure 28. Exchanged power between AC and DC system. 
transferred to the electrolyser. If the total electric power generated by the PV and wind turbine systems is less than the demand, power will be supplied from the fuel cell system. Amount of power that is exchanged between $\mathrm{AC}$ and DC parts according to APR comments and CCI in $20 \mathrm{sec}-$ onds is shown in Figure 28.

\section{Conclusion}

In this paper, the dynamic behavior of the hybrid system and the diesel generator with linear load are tested under wind speed variations. The controller has been designed to exchange the power between two parts. This system has a voltage and frequency controller to control power between AC and DC parts. According to the wind speed and load variations, a PID controller with fuzzy logic is designed. Switching command between AC and DC parts is carried out with CCI. Controller system has to be able to keep values in the base rate. It depends on other renewable energies too. The main aim of this work is the hybridization of the renewable energy sources with fuel cell and battery system by suitable power controllers. The system and its control strategy present a great performance under variable wind speed and load power necessity. Applying fuzzy logic to design a PID controller can provide uncertainty in the load forecast.

\section{References}

1. Baumann L, Boggasch E, Rylatt M, Wright A. Energy flow management of a hybrid renewable energy system with hydrogen. Innovative Technologies for an Efficient and Reliable Electricity Supply (CITRES), 2010 IEEE Conference on. 2010 Sept 27-29; Waltham, MA. p. 78-85.

2. Li C, Liu G. Optimal fuzzy power control and management of fuel cell/battery hybrid vehicles. J of Power Sourc. 2009; 192(2):525-33.

3. Onar OC, Uzunoglu M, Alam MS. Modeling, control and simulation of an autonomous wind turbine/photovoltaic/ fuel cell/ultra-capacitor hybrid power system. J of Power Sourc. 2008; 185(2):1273-83.

4. Jin K, Ruan X, Yang M, Xu M. Power management for fuel-cell power system cold start. Power Electronics, IEEE Transactions on. 2009; 24(10):2391-95.

5. Boettenr DD, Paganelli G, Guezennec YG, Rizzoni G, Moran MJ. Proton exchange membrane fuel cell system model for automotive vehicle simulation and control. J of Energ Resour Tech. 2002; 124(1):20-27.

6. Zhang F, Shi Q, Wang Y, Wang, F. Simulation research on wind solar hybrid power system based on fuzzy-PID control. International Conference on Electrical Machines and Systems. 2007. ICEMS. 2007; 338-342.

7. Khan MJ, Iqbal MT. Dynamic modeling and simulation of a small wind-fuel cell hybrid energy system. Renew Energ. 2005; 30:421-39.

8. El-Shatter TF, Eskander MN, El-Hagry MT. Energy flow and management of a hybrid wind/PV/fuel cell generation system. Energ Convers Manag. 2003; 47(9-10): 1264-1280.

9. Gao W. Comparison of a fuel cell-battery hybrid power train and a fuel cell-ultra capacitor hybrid power train. IEEE transactions on Vehicular Technology. 2005; 54: 846-55.

10. Sapru K, Stetson NT, Ovshinsky SR. Development of a small scale hydrogen production storage system for hydrogen applications. Proceedings of the 32nd Intersociety Conference, 1997 Jul 27-Aug 1; Honolulu, HI. 1997. p. 1947-1952.

11. Onar OC, Uzunoglu M, Alam MS. Dynamic modeling, design and simulation of a wind/fuel cell/ultra-capacitorbased hybrid power generation system. J of Power Sourc. 2006; 161(1): 707-22.

12. Schouten NJ, Salman MA, Kheir NA. Management strategies for parallel hybrid vehicles using fuzzy logic. Contr Eng Pract. 2003; 11(2): 171-77.

13. Gorgun H. Dynamic modeling of a proton exchange membrane (PEM) electrolyser. Int J Hydrogen Energy. 2006; 31(1):29-38.

14. Mengi OO, Altas IH. Fuzzy logic control for a wind/battery renewable energy production system. Tobitak, Turk J Elec Eng \& Comp Sci. 2012; 20(2):187-206. 